\title{
The Network Structure of the Malawi Interbank Market: Implications for Liquidity Distribution and Contagion around the Banking System
}

\author{
Esmie Koriheya Kanyumbu \\ Reserve Bank of Malawi, Lilongwe, Malawi \\ Email: korismie@yahoo.co.uk
}

How to cite this paper: Kanyumbu, E. K. (2020). The Network Structure of the Malawi Interbank Market: Implications for Liquidity Distribution and Contagion around the Banking System. Open Journal of Business and Management, 8, 2740-2760. https://doi.org/10.4236/ojbm.2020.86170

Received: October 22, 2020

Accepted: November 22, 2020

Published: November 25, 2020

Copyright $\odot 2020$ by author(s) and Scientific Research Publishing Inc. This work is licensed under the Creative Commons Attribution International License (CC BY 4.0).

http://creativecommons.org/licenses/by/4.0/

\section{(c) (i) Open Access}

\begin{abstract}
The study aimed to understand the network structure of the Malawi interbank market, a relatively small but active market. To do this, we constructed a network of banks using aggregated interbank loan amounts. We then analyzed the topological characteristics of the interbank market network structure and discussed the implications of such characteristics in terms of liquidity distribution and contagion in the Malawi banking system. We establish that the Malawi's interbank network is fairly dense with a significantly high clustering and a small average path length. This implies that liquidity is able to flow in a fairly efficient manner within the network. Due to the relatively high connectivity of the network, entry or exit of a bank, on average, is likely to have little impact on the ability of other banks to lend and borrow from each other. The high connectivity further implies that banks are able to monitor each other's behaviour. This may result into liquidity hoarding and may force some banks to get liquidity at a higher cost than the one prevailing on the market. The relatively high clustering and a small average path length further implies that the interbank participants are more vulnerable to contagion than in random networks. We further argue that because of the strong connectivity, the network may not be resilient to an operational shock affecting one or more of the banks. In this case, the impact of an operational shock may be felt not just on the connectivity of the network but rather on the availability of liquidity within the banking system.
\end{abstract}

\section{Keywords}

Interbank, Network, Liquidity, Contagion

\section{Background to the Study}

Interbank markets are markets where banks lend and borrow funds from each 
other, mainly for the sake of meeting their daily liquidity needs. Although most interbank markets host both overnight and longer-term loans, the overnight interbank market plays a number of crucial roles and is the main focus of this thesis. From the macroeconomic point of view, the interbank market is important in three different ways. Firstly, the interbank market facilitates a smooth functioning of the financial system by acting as a channel for redistributing banking system liquidity and hence takes care of most of the liquidity imbalances experienced in the banking system. When the interbank market is efficient, equilibrium is restored in the banking sector and any undesirable liquidity gaps are closed before the central bank has to take action. This restores financial stability which is one of the key interests of central banks around the globe. Secondly, the interbank market acts as a transmission channel of monetary policy. This is crucial especially in modern days where most economies have moved from monetary aggregate targeting in favour of either interest rate targeting or inflation targeting in their conduct of monetary policy. Signals from a well-functioning interbank market, through the interest rate and credit channels, provide an effective way of discovering prices in money markets. This is because the interbank market is the only well-established market where the overnight rate, the rate that provides the shortest end of the yield curve, is determined. The overnight rate is key to financial markets since it acts as a guide for other market rates that affect the key macro-variables of the economy. This implies that a well-functioning interbank market is an important guide for the pricing of financial products such as loans, mortgages, futures, options and swaps. Moreover, interbank rates, to a certain extent, reflect the stance of monetary policy since they are highly affected by both adjustments to policy rates as well as central banks' liquidity management efforts. Thirdly, because interbank markets are associated with unsecured loans, trading in these markets is mainly based on trust that participating banks have for each other. From that point of view, we would expect that a well-functioning interbank market would be able to put in place strong disciplining mechanisms among its participants. By providing or denying loans and pricing liquidity according to the riskiness of counterparts, interbank markets offer an additional hand to central banks' macro-prudential regulation which continues to be challenged by innovations in the banking industry, information asymmetry, weak legal frameworks and government intervention, among other things. Thus, the existence of an active interbank market can expose some of the hidden risks in the banking system and assist the central bank to take the necessary actions and be able, therefore, to avoid potential crises.

The effects of the US subprime mortgage crisis of 2007 and the collapse of Lehman Brothers in 2008 on global financial markets have been well documented in literature, intensifying the crucial role played by interbank markets across economies. Activities and behaviours of different interbank markets continue to attract a lot of attention among researchers and financial markets ex- 
perts following the unusual behaviour of interbank markets that was observed after the global financial crisis. Precisely, the world observed a breakdown of liquidity in the normally robust financial markets and failure of central bank intervention to enhance liquidity (Brunetti et al., 2015). It was further observed that linkages among financial institutions were the main source of systemic risk (Sahabat et al., 2017).

Such observations have raised awareness on the part of stakeholders, especially central banks, to begin analyzing the resilience of the financial system based on the connectedness patterns within the interbank network. Although such observations raise interesting research questions in financial economics in general, much attention has been directed towards the linkages that exist in interbank markets and how such linkages are considered to have played an important role in transmitting serious losses during the crisis (Xu, 2016). Interbank markets have, consequently, quickly become one of the key gauges of market tensions and expectations in many economies. Due this, research on interbank network analysis remains very important as it contributes to the development of a stress testing framework for assessing systemic risk in the banking systems.

The interbank market is classified as a unique money market due to one of its stand-alone features: loans in interbank markets are both secured and unsecured. Because some loans in the interbank markets are not collateralized, borrowing and lending in these markets, especially in the unsecured segment of the market, depend on the trust among participants. Because of this aspect, interbank markets are associated with close relationships that result into complex financial institutional networks. As different markets continue to evolve, these highlighted aspects of the interbank market are becoming more important from both policy and research point of view hence interbank markets require formulation of specific policies concerning the way in which liquidity is funded.

As pointed out by Brink and Georg (2011), the financial crisis of 2007/08 highlighted, among other things, the necessity of macro prudential oversight on financial systems in addition to micro prudential supervision. To ensure stability of the financial system, it is important not only to monitor the strength of the individual financial institutions, but also to analyze the network structure that they form due to their various interlinkages. Because trading in interbank markets depends on trust, a well-functioning interbank market is able to put in place strong disciplining mechanisms among its participants. By providing/denying and pricing liquidity according to the riskiness of counterparts, interbank markets offer an additional hand to central banks' macro-prudential regulation which continues to be challenged by sophistications in the banking industry, information asymmetry, weak legal frameworks and government intervention, among other things. Thus, studying the network structure of an active interbank market can provide an incentive to look for some of the hidden risks in the banking system. This can assist central banks to take the necessary actions in the banking system and hence avoid some potential crises. 
Among different forms of interconnections between banks, interconnections through interbank loans are among the most important ones due to two main reasons. Firstly, interbank interconnections are convenient for the enhancement of liquidity allocation since they provide a remedy to liquidity-constrained banks which would otherwise pay hefty premia to get funds elsewhere. This is specifically true for smaller banks who, in most cases, have to pay hefty premia to get funds from larger peers or regulators in times of liquidity shortages. Secondly, such interconnections are associated with risk sharing in the banking system. While risk sharing may be good in some cases, it may also mean that some risks are allocated to market players who may not be able to bear their portion of risk. That situation may lead to the amplification of shocks in times of crisis.

The study documents the network structure of the Malawi interbank market by analyzing the topological characteristics of the network structure its implications in terms of liquidity distribution and contagion in the banking system. We implemented thus by describing and mapping the interbank network in Malawi and its evolution using a simple network model. Such analysis is important for discussion on financial stability since it has the potential of opening up new opportunities for systemic risk assessments of the market. Moreover, this contributes specifically to an understanding of the stability and robustness of a network of liquidity flows in response to an operational disturbance given that different network properties give rise to different degrees of resilience to disturbances. In particular, the properties of an interbank network may have important implications for the flow of liquidity through the system in stressed circumstances. Generally, the higher the connectivity of the system, the faster liquidity is expected to flow to the stricken bank(s). Moreover, banks that exhibit a low in degree are likely to be more vulnerable to disturbances than other banks, as the removal of one link will severely limit the flow of incoming funds. On the other hand, banks with high out degrees have the potential to affect more counterparties if their payment processing is disrupted. In a near-complete network, however, link weights, rather than node, degree and connectivity, play a larger role.

\section{Related Literature}

The network theory is generally associated with the study of graphs which are represented either as symmetric relation or asymmetric relation among discrete objectives. Such a representation has proved to be useful in different disciplines in the study of different relationships. In intelligence agencies, the theory is applied in identifying criminal and terrorist networks from traces of communication that they collect and then identifying the key players in these networks. In social network websites like Facebook, the network theory is used in identifying and recommending friends based on friends of friends. In epidemiology, the network theory is applied to track the spread of diseases like HIV/AIDS. In the current global Covid-19 situation, the network theory could be useful for the 
track and trace efforts that are being applied by different countries. The theory can also be used to study mobile payments and their associated risks (Dospines$\mathrm{cu}, 2012)$. In financial economics, especially following the financial crisis highlighted earlier, the network theory has specifically become useful in explaining the dynamics of the interbank market. From a financial market perspective, a network is defined as a set of nodes representing financial institutions in a particular market and set of links defining the relationships between those nodes. Links may exist between the nodes and they may be directed or undirected ${ }^{1}$. While central banks have applied the network theory for mapping different interlinkages between financial institutions, network theory, has become specifically useful in studying the structure of the banking system that is composed of banks that are connected by their interbank bilateral exposures.

Studying the interbank market as a network is important to both researchers and policy makers because it assists in the understanding of how banks are related and the importance of each of the banks in the functioning of the interbank market. Using the network approach, stakeholders are able to find the degree of heterogeneity in the interbank market and use that to determine the disintegration of the network in the event of pressure. For instance, the network approach is able to show the interconnection structural differences between banks before and after a specific shock by measuring the distance of the connectedness within different time periods. Although the network approach may not necessarily be used as a tool to identify potential future crises, interbank connectivity pattern can be used in estimating the occurrence of pressures in the financial system in the future (early warning signals). It further assists in the identification of sources of potential crises in different markets. The network approach can be used to gauge financial contagion in the banking system since the structure of the network affects the degree and speed at which financial crises spread throughout the market. The network approach further has the ability to expose patterns in interbank relationships that may not be clearly observed numerically. For instance, the approach has assisted in the understanding of the interconnectedness within the banking system which proved to be a key driver of systemic risk in the 2008 global financial crisis (Brunetti et al., 2015). Thus, using the network approach, stakeholders are able see some aspects of the market, including levels and changes in financial interconnectedness, that have become crucial for global financial stability.

The network approach is often complemented by the core-periphery model in the determination of the structure of the connectedness by classifying the group of banks acting as core/center or periphery. The theory was introduced by Borgatti and Everett (2000) but it was pioneered by Craig and von Peter (2014) in its application to interbank markets. According to the core-periphery model, the interbank market is split into two subsets; the core market and the periphery market. The "core", consists of banks that are central to the system and are able ${ }^{1}$ According to Brassil and Nodari (2018), directed links contain information on the direction of the flow (e.g. a loan going from bank A to bank B) while undirected links only show that a flow exists. 
to lend and borrow from all the other banks in the core and other banks outside the core while the other subset, the "periphery" do not transact directly among themselves but depend on lending and borrowing from banks. This implies that while some participants are able to trade with the market as a whole, there exists some parallel markets outside the general market, where liquidity can be supplied for the banks that, due to some reasons, are unable to tap into the liquidity that is available in the main interbank market.

Earlier research on interbank market, like the seminal work of Poole (1968) focused on importance of this market in hosting the first step of monetary policy transmission mechanism. Such literature includes the seminal work of Poole (1968). In more recent research, efforts to understanding these markets include the understanding of interconnectedness and how such connections enhance risk sharing and amplification of shocks in times of crisis. The network approach has specifically been applied in that line of research. Such efforts have mainly followed the realization that micro prudential supervision and regulation is inadequate on its own to identify potential route of contagion and assess the stability of financial system. It is no longer debatable, therefore, that the systemic importance of one bank depends not only on the properties of that bank, but also on the properties of the whole market. This has brought in interest in interbank connections and these connections are looked at from different perspectives.

Brassil and Nodari (2018) applied the network approach to study interconnection in the Australian interbank market using aggregated loan-level data and constructed a network for each quarter for Australian banks for the period between 2005Q2 and 2016Q1. The results showed that out of the 42 participating banks in the Australian interbank market, on average, there existed 420 directed loan relationships. The results further showed that while the networks on the Australian interbank market have higher densities, the relationships were found to be sparse. Some researchers have concentrated on interbank connections and how such connections can affect the risk of the whole banking system. In Xu (2016), the network approach was applied to establish contagion in the US interbank market using message passing algorithm. The study used transactions between US banks for the period between 2006Q1 and 2010Q3. The results of the study showed that while dense networks and sparse networks perform differently in network properties and in contagions triggered by single-bank failures, the two perform the same when contagions are triggered by multiple-bank failures. In Brink and Georg (2011), the interbank market network of South African banking system was analyzed using the data from March 2005 to June 2010 by constructing an index that renders a particular bank's systemic significance less predictable and less constant. The study used a unique dataset of South African Multiple Options Settlements (SAMOS) system. The results showed that South African interbank system had been largely stable and resilient during the period covered in the study, even in times of great distress on the international financial markets. In addition, the study concluded that the number of banks participat- 
ing in the South African interbank market was almost constant and there was a high level of interconnectedness during the analyzed period. Because of the observed strong interconnectedness, the study established a high level of liquidity allocation and risk sharing in the South African interbank market.

Some studies have been interested in specific banks' positions in the market network and how such positions affect both liquidity access and provision. A study by Gabrieli and Georg (2016) is one example of such studies. In Gabrieli and Georg (2016) a dataset of all the European banks was used to study the liquidity reallocation among the banks. The study specifically, dwelt on how a bank's characteristics affect its ability to borrow and lend on the overnight interbank market. Using Ordinary Least Squares (OLS), the study established that a bank's position in the interbank network, as measured by various measures of centrality in networks, has a significant impact on both liquidity provision and access. Precisely, banks with higher network centrality were found to provide more liquidity in the interbank market. Such banks are also willing to lend funds at cheaper prices. Similarly, banks with higher network centrality were found to have access to more liquidity and borrow funds on the interbank market at cheaper prices. This implies that a bank's position in the interbank network plays a role in the determination of both interbank traded volumes and rates.

The network approach has also been applied to compare the behaviour of banks during normal times and during times of financial crisis. Brunetti et al. (2015) studied the behaviour of the European interbank market before, during and after the financial crisis. They established that while the two types of networks defined in the study, the correlation network ${ }^{2}$ and the physical network ${ }^{3}$ behaved the same way before the crisis, the correlation network showed an increase in interconnectedness during the crisis while the physical network highlighted a significant decrease in interconnectedness. It was further observed that physical networks were able to forecast liquidity problems while financial problems were better forecasted by correlation networks. The network approach has also been importantly used to understand how lending conditions in the interbank market are affected by the networking of banks. Blasques, Brauning and Lelyveld (2018), estimated the structural micro-founded dynamic network model on the network statistics of the Dutch unsecured interbank market using monthly data from February 2008 to April 2011. The study was specifically interested in the characteristics of interbank markets as can be explained by two main aspects of this type of market, namely, liquidity uncertainty and peer monitoring in interaction with counterparts. The study found that Dutch banks form long-term lending relationships that are associated with improved credit conditions and that the lending networks exhibits sparse core-periphery structure. Such findings support the crucial role played by lending/borrowing relationship in the determination of interbank traded volumes as well as the interbank rate. ${ }^{2}$ Based on publicly traded bank returns.

${ }^{3}$ Based on interbank lending transactions. 
These findings agree those of Schumacher (2016), who applied the network approach to understand how the lending conditions in the Swiss franc money market are affected by the networking of banks. The findings established that there is a difference in the lending conditions for the secured and the unsecured segments of the market. While clustering ${ }^{4}$ is more pronounced in the unsecured segment of the market which serves as a social collateral, trust plays a minor role in the secured part of the market where physical collateral is involved. Generally, banks with stronger relationships in the interbank market (higher clustering coefficients) are offered better trading conditions in terms of both trading volume and rates.

The network approach has also been applied to establish the presence of core and periphery market structure in particular interbank markets and how such a structure affect lending and borrowing in interbank markets. Craig and von Peter (2014) studied the bilateral interbank exposures among 2000 German banks from 1999 to 2012. The study provided evidence that most banks in Germany do not lend to each other directly but through money center banks. Such money center banks act as intermediaries for the interbank market. In Oduor et al. (2014), it is observed that incompleteness and segmentation in Kenyan interbank impede the effectiveness of monetary policy, especially in the short run and during periods of liquidity volatility. A similar observation was also noted in Colliard et al. (2016) who documented the impact of segmentation between the core and the periphery markets in European interbank markets. In addition, it is highlighted that apart from raising the bargaining power of periphery banks that are connected to the core market, and raising the price dispersion in the interbank market, segmentation was found to raise inefficient resort to the central bank standing facilities.

As can be noted from the reviewed literature, limited attention has been devoted to study the network structure of interbank markets of low income countries like Malawi. Although most low-income economies like Malawi were not directly affected by the last financial crisis, contagion via the interbank market remains one of the key concerns of the central banks because possible chances of encountering such crises remain in such countries. Learning from the banking crises of the 1980s and 1990s, crises in low-income generally take longer to resolve than in other groups of countries. Moreover, chances of macroeconomic and banking system fragility still exist in these countries and crises can still arise following strides in financial deepening and sophistication of financial systems in these countries. Moreover, due to relaxation in bank ownership restrictions observed in modern low-income banking sectors, it has become more relevant than before, to study the interbank network structure of these markets in order to observe and analyze possible sources of crises, levels and the speed of such crises and discuss possible relevant policy actions that can be taken to make such ${ }^{4}$ Having a common trading partner. 
markets resilient to possible identified shocks. Getting a better picture of the network structure is therefore a crucial step in developing systematic risk assessment of the interbank market.

\section{The Malawi Interbank Market}

Network properties are market-specific across different countries because of the different characteristics of specific markets. The interbank market in Malawi is relatively small, but has been active for its entire life period. Trading in Malawi's interbank market started in 2001 and since its inception, trading, in terms of volumes, has generally been increasing (Figure 1).

Generally, banks lend or borrow from the interbank market in relation to their predicted excess reserves that is calculated as any amount of liquidity that is above or below the Liquidity Reserve Requirement (LRR) prescribed by the RBM from time to time. Consequently, the amount of funds traded on the interbank market, to a certain extent, reflects the liquidity condition in the banking system and the monetary policy stance of the central bank, the Reserve Bank of Malawi (RBM), as shown in Figure 2.

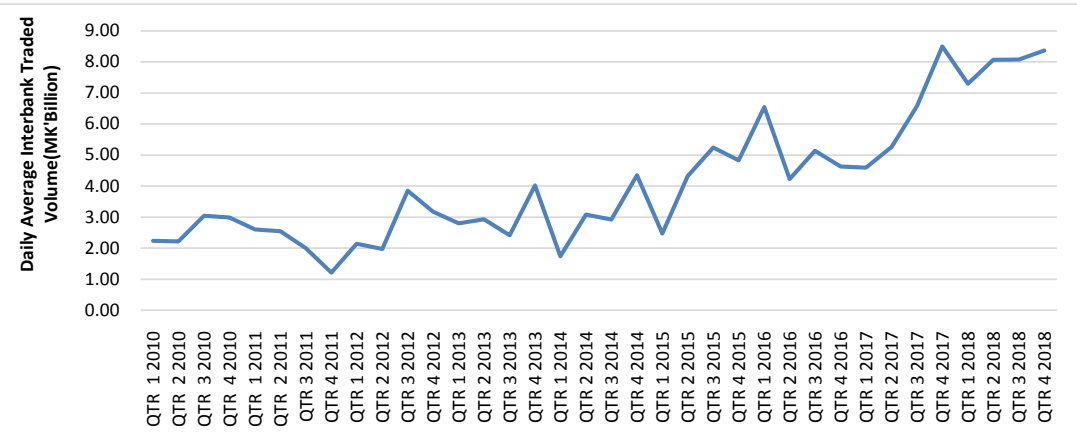

Figure 1. Interbank traded volume in billions of Malawi Kwacha ${ }^{5}(\mathrm{MK})$ for the period 2010-2018. Source: Reserve Bank of Malawi (RBM) data.

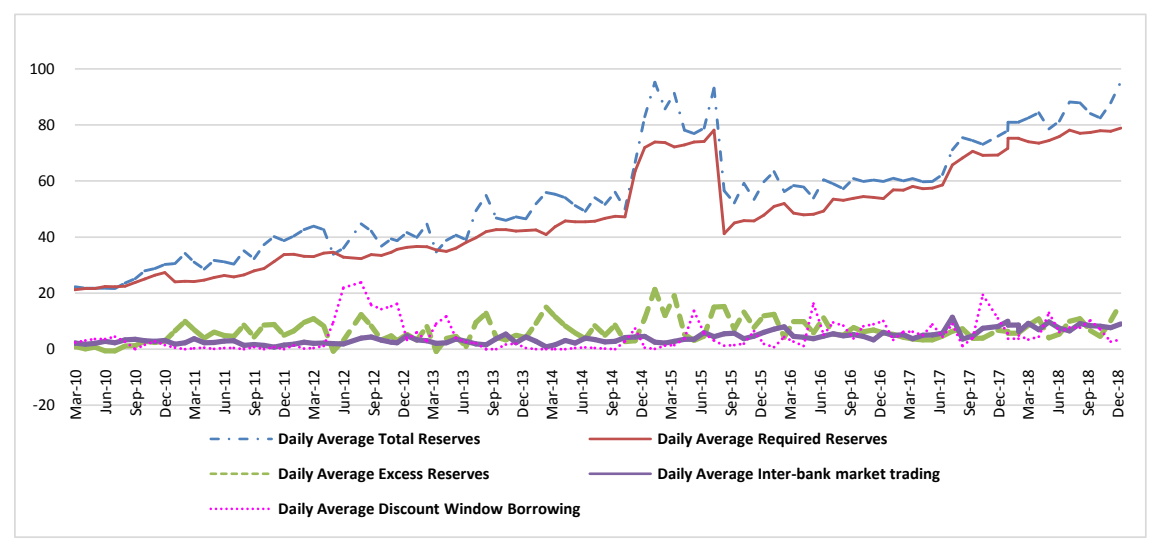

Figure 2. Banking system liquidity and interbank market (MK'Billion). Source: RBM data.

${ }^{5}$ The Malawi Kwacha (MK) is Malawi's local currency. 
Unlike other more developed interbank markets, trading in the interbank market in Malawi is restricted to commercial banks and discount houses that are registered and operate in the country. Trading across boarder has, so far, not been registered and all the transactions are in the country's local currency (the Malawi Kwacha).

Although the interbank market in Malawi is characterized by different maturity profiles, over 95 percent of trading (in terms of both volumes and number of trades) mature overnight and funds are on both collateralized and uncollateralized bases. The tracked transactions in the interbank market are those carried in local currency (Malawi Kwacha) since foreign exchange interbank lending and borrowing have not, to our best knowledge, been registered. It is also noted that the interbank market in Malawi depicts some characteristics of segmentation (Tiriongo \& Kanyumbu, 2019). Like other markets of similar nature, both trading and pricing of liquidity in this market depends on credit assessment that banks conduct on each other. Access as well as the pricing of interbank loans, therefore, reflects a bank's perceived level of risk. Such a disciplining role points towards the potential for the market to support to macro-prudential regulation by the central bank.

\section{Methodology and Data}

In general terms, a network consists of nodes and links. In this study, each node stands for a bank and each link connecting two nodes bears interbank trading relationship between the two corresponding banks. Although a network can be either directed or undirected, the study was interested in the directed network for the analysis of the interbank market in Malawi. Node characteristics and the links associated with individual nodes have different implications depending on whether a bank is a borrower or a lender. The study models Malawi's interbank loan flows as a directed network. This is because directed network brings out good discussions for policy making of central banks. We presented banks as nodes in the network and traded volumes between banks form the links between these nodes. We define these links as being "directed" in such a way that if bank $\mathrm{X}$ only lends (but does not borrow) funds to bank $\mathrm{Y}$ then there would be a directed link from $\mathrm{X}$ to $\mathrm{Y}$ but not one from $\mathrm{Y}$ to $\mathrm{X}$. In a situation where both banks $\mathrm{X}$ and $\mathrm{Y}$ extended loans to each other, we have two directed links, one in each direction. The weight attached to a link is proportional to the value or volume of interbank loans passing through that link. The design of the interbank market in Malawi has been in such a way that all participants can technically borrow and lend to each other. The market can therefore, in principle, be modelled as a complete network. The empirical work analyzed the extent to which each of these links is used in practice and hence discussed the implications of that on the flow of liquidity and contagion around the banking system.

The study uses aggregated interbank loan amounts to construct a network of 
the banks operating in Malawi. For a thorough analysis of the network structure of Malawi's interbank market, the study uses network constructed in such a manner for the last quarter of 2018, the latest quarterly data available to the author. To understand the interconnections and the evolution of such interconnections, the study further uses aggregated interbank loan amount data to construct a network for each quarter for banks operating in Malawi for the period 2010Q1 to 2018Q4. Comparing a number of network characteristics for different periods is vital because there has been a number of policy changes ranging from LRR percentage, the observance period and to how the LRR has been calculated during the period. It is of interest therefore, to learn how such changes affect the interbank network and its characteristics and implication of such changes on financial stability. Moreover, there have been changes to the number of banks operating in Malawi in different periods. It is of interest therefore, to analyze how entry and exit of banks from the system affect the strength of the network. The descriptive statistics of the data for the 32 quarters of interest is presented in $\mathrm{Ta}$ ble 1 .

\section{Results: Network Characteristics of Malawi's Interbank Market}

\section{Nodes, Links and Degree}

The number of nodes defines the size of a network. For the sample period used in the study, the number of nodes varies from 10 to 13. Figure 3 plots the number of banks participating in Malawi's interbank market as at 2018Q4 as borrowers and/or lenders. It is observed that as at 2018Q4, there were 10 participants in this market. Figure 4 indicates that there have been variations in the number of participating banks during the study period. The average size of the Malawi interbank network on any given quarter is 12 nodes. The largest network is that of 13 banks and that appeared in 20 different quarters. The smallest network is that of 10 banks and appeared in each of the last three quarters of the sample period (2018Q2, 2018Q3 and 2018Q4).

Table 1. Descriptive statistics of key network measures.

\begin{tabular}{ccccccc}
\hline & Nodes & Degree & Links & $\begin{array}{c}\text { Clustering } \\
\text { Coefficient }\end{array}$ & $\begin{array}{c}\text { Average Path } \\
\text { Length }\end{array}$ & $\begin{array}{c}\text { Graph } \\
\text { Density }\end{array}$ \\
\hline $\begin{array}{c}\text { Number of } \\
\text { observations }\end{array}$ & 36 & 36 & 36 & 36 & 36 & 36 \\
Mean & 12 & 5.803 & 70 & 0.581 & 1.479 & 0.528 \\
Maximum & 13 & 8 & 96 & 0.767 & 1.842 & 0.756 \\
Minimum & 10 & 3.385 & 44 & 0.324 & 1.244 & 0.282 \\
Std Deviation & 1 & 0.993 & 12 & 0.105 & 0.153 & 0.118 \\
\hline
\end{tabular}




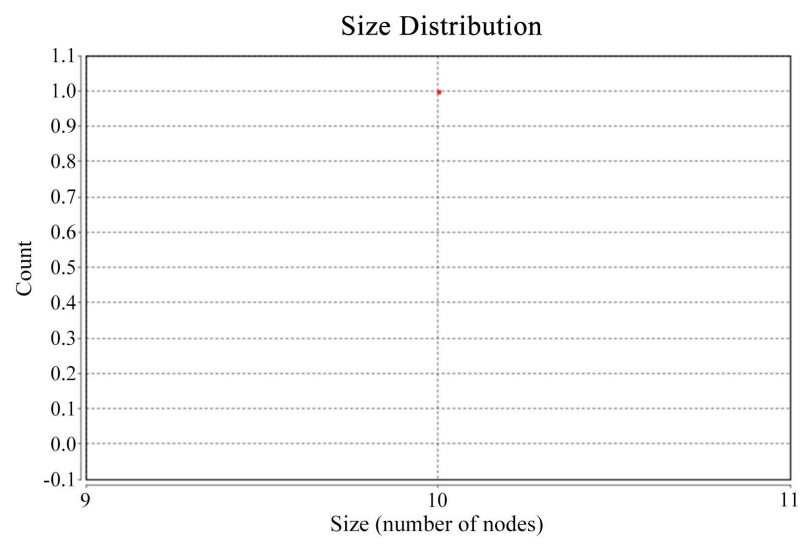

Figure 3. Size of the Malawi's interbank network as at 2018Q4.

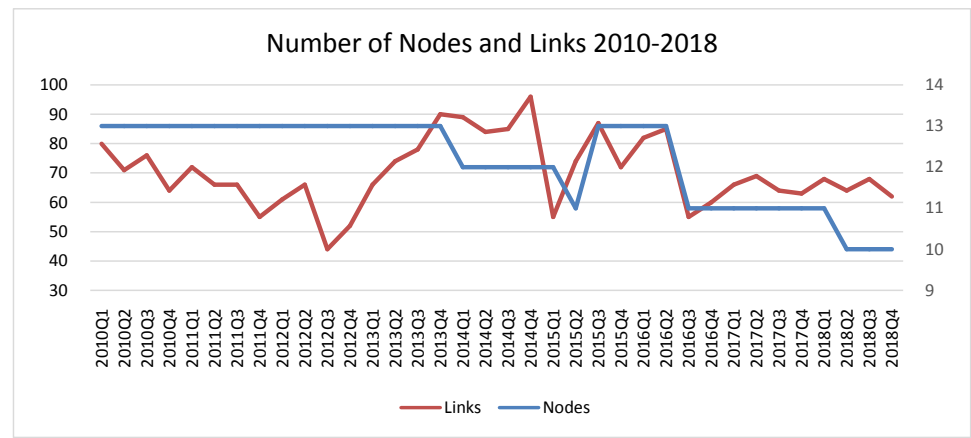

Figure 4. Changes in the number of nodes and links in Malawi's interbank network (2010Q1-2018Q4).

Turning to the evolution of the network over time, Figure 4, Figures 5-7 illustrate that the characteristics of the interbank network has not been stable even in times when the number of market participants has been stable. For instance, although the number of participating banks did not change between 2010 and 2013, the number of links has been changing and has been volatile during that period. This is against findings of some studies of similar nature. For instance, Soramaki et al. (2006) found that USA interbank connectivity patterns change when there is a disruption to a number of financial systems and infrastructure. The Malawi interbank network structure does not support the change in connectivity due to the number of banks trading in the market. However, it may be the case that connectivity has been changing due to change in infrastructure.

Figure 8 provides a visualization of the Malawi's interbank network on a sample quarter (2018Q4). The thickness of the links is proportional to their weight, defined as the value of the interbank loan passing through the link. It is clear that interbank trading between participating banks forms a fairly well-connected network. The high level of connectivity is confirmed by the descriptive statistics presented in Table 2. The network displays both a fair connectivity (68.9\%) and a short average path length (1.322), implying that most banks have directed links with most banks in the market and the average degree ${ }^{6}$ of a node is 6.2; that is, on average, more than six links originate from each node 
and more than 6 links end at each node. However, the network could be classified as less complete compared to the interbank payment flows of the United Kingdom ${ }^{7}$ where connectivity was found to be as high as $88 \%$, with the average path length of 1.1 (Becher et al., 2008).

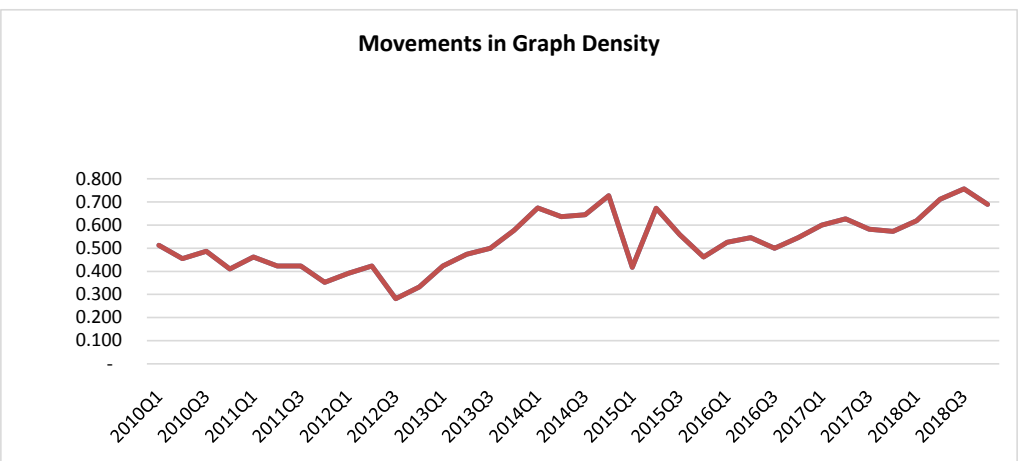

Figure 5. Changes in Malawi interbank network completeness (2010Q1-2018Q4).

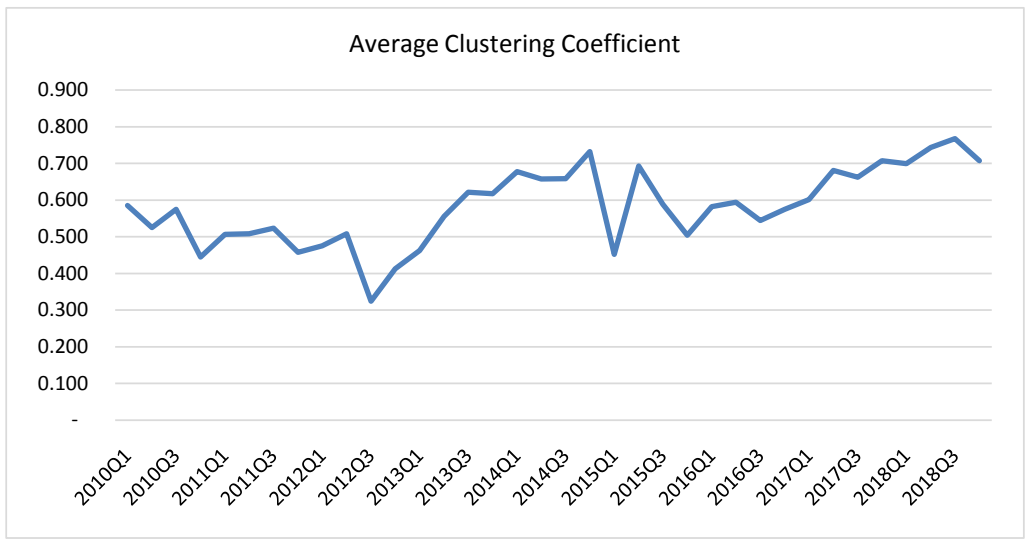

Figure 6. Change in Malawi's interbank network clustering.

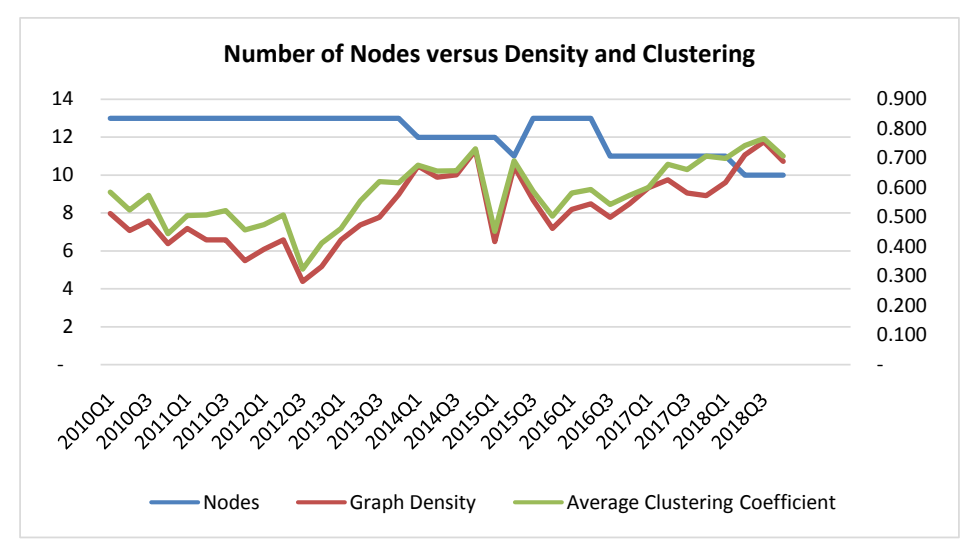

Figure 7. Relationship between movements in nodes, density and average clustering coefficient.

${ }^{6}$ The degree of a node refers to the number of links that originate (out degree) or terminate (in degree) at that node.

${ }^{7}$ Although that was just for one day, 17 May 2007. 


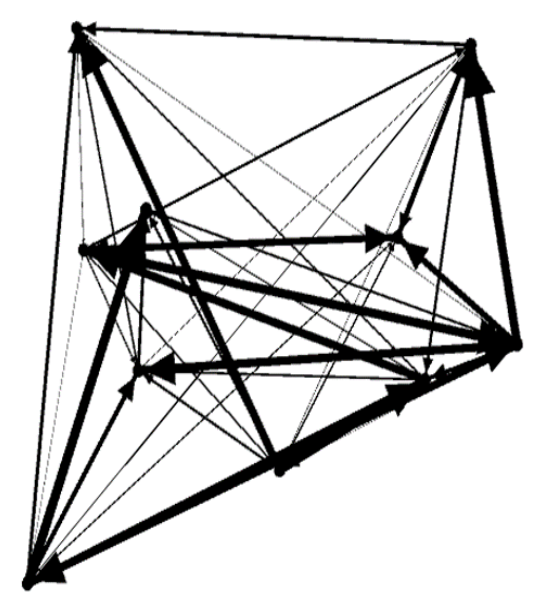

Figure 8. Value-Weighted topology of Malawi interbank network (2018Q4).

Table 2. Properties of the Malawi interbank network as at 2018Q4.

\begin{tabular}{cc}
\hline Number of Nodes & 10 \\
Average Degree & 6.2 \\
Number of edges & 62 \\
Connectivity (per cent) & 68.9 \\
Maximum/ Average/ Minimum out degree & $9 / 6.2 / 3$ \\
Maximum/ Average/ Minimum in degree & $8 / 6.2 / 5$ \\
Average path length & 1.322 \\
Average clustering Coefficient & 0.707 \\
\hline
\end{tabular}

\section{Completeness of the Network}

The degree of completeness of a network in this study is measured by the number of links relative to the number of possible links, given the number of nodes. For a complete network, for instance, a directed network with 10 nodes (like the one in 2018Q4) implies 90 possible links ${ }^{8}$. The average number of links per quarter during the sample period is 70 . It ranges from the smallest with 44 edges, to the largest with 96 links. Because the number of nodes varies throughout the period, we use a measure of network completeness that takes care of the number of nodes when making comparisons. In this case, we use the graph density, calculated as number of links divided by number of possible links. This number ranges from 0 to 1 , where 1 implies a complete network and 0 implies no connectivity at all.

As can be observed from Figure 4, although the number of nodes (participating banks) remained unchanged between 2010Q1 and 2013Q3, activity, as shown by the number of links has been changing. It is further noted that there was a consistent increase in number of links between 2012Q3 and 2013Q4. This increase in connectivity in the interbank market was associated with the tight ${ }^{8}$ The number of all possible links is calculated as $n(n-1)$, where $n$ is the number of nodes. 
monetary policy that was being implemented by the RBM. A bigger part of the period is associated with the period that the RBM set the LRR ratio at twofold: at $15.5 \%$ to be observed fortnightly and $12.0 \%$ to be observed daily. Because banks were supposed to keep $12.00 \%$ of the total deposits with the central bank daily while at the same time making sure they meet the $15.5 \%$ fortnight LRR, banks could not afford keeping extra cash untraded as demand for such cash was there most of the times. Likewise, when the RBM revised the LRR to $7.5 \%$ observed daily from the $12.00 \%$ that was being observed daily in November 2015, we notice a significant drop in connectivity in 2015Q4. Changes in network completeness for Malawi interbank market during the sample period is in shown in Figure 5.

Figure 5 shows a general increasing trend in network completeness during the sample period. The average density is 0.528 . The lowest density of 0.282 is observed in 2012Q3 while the highest density of 0.756 is observed in 2018Q3. As at 2018Q4, density for the Malawi interbank market stood at 0.689 . This implies that the interbank network Malawi is relatively dense, with a degree of completeness averaging $52.80 \%$ compared to the extremely sparse fed funds network (Bech \& Atalay, 2010) and the network of Fedwire payments (Becher et al., 2008) with a degree of completeness less than $1 \%$. As can be observed from Figure 5, the interbank network completeness was increasing continuously from 2012Q3 until 2014Q1.

\section{Clustering}

Clustering is a measure of the degree to which two banks, which are connected to a specific bank, are also connected to each other. In this study, the neighborhood of a node (a bank) is defined as the set of nodes that are connected to that node. If every node in the neighborhood of a particular node is connected to every other node in the neighborhood of that node, then the neighborhood is said to be complete and will have a clustering coefficient of 1 . However, if no nodes in the neighborhood of a particular node are connected, then the clustering coefficient will be 0 . The average clustering coefficient over all nodes in the network determines the network clustering. Analysis of interbank network clustering helps to understand the extent of liquidity flows in the banking system and how contagious a crisis can be. The actual distribution of links between banks affects the stability of the banking system and the possible contagion after a main shock. If all banks are connected to all other bank (a complete network), a shock to a single bank can easily be shared between the banks and the stability of the system is likely to be safeguarded. On the other hand, when the network is clustered, spillover of some of the banks can become considerable. During the study period, the average clustering coefficient for the whole interbank market was 0.581 . In our sample period, the smallest average clustering coefficient is 0.324 and is observed in $2012 \mathrm{Q} 3$ while the largest average clustering coefficient of 0.767 is observed in 2018Q3. As at 2018Q4, the average clustering coefficient stood at 0.707 . 
The clustering coefficient for Malawi's interbank market is lower compared to the one found by Roukny et al. (2014) for the German credit network between 2002 and 2012. For the German market, the clustering coefficient decreased from 0.87 to 0.80 . However, the clustering is high compared to the 0.466 found by Anand et al. 2015 for German interbank market from the second quarter of 2003. Vandermarliere et al. (2015) employed data for Russian interbank network between 1998 and 2005 and found the average local clustering coefficient (over all the nodes and time periods) to be 0.198 . Bech and Atalay (2010) explored the data for Federal funds market (a market for overnight borrowings between banks) between 1997 and 2006 and found that the in-clustering-coefficients lie between 0.2 and 0.4 , while the out-clustering-coefficient was between 0.1 and 0.2. The Malawi interbank market clustering numbers imply that there is a limit to which every bank in the network trades with any other bank. This means that liquidity may not always flow smoothly throughout the system. This justifies what is noted in Tirongo and Kanyumbu (2017) that some banks in this market access the central bank's Lombard facility for their liquidity needs even when the general market is liquid. On the other hand, because there is a limit to which banks can trade amongst themselves, contagion is expected to be limited in this market. It is noted that properties of banking network may vary a lot across countries, or among different types of interlinkages. The difference in banking network properties could be, among other things, due to availability of central bank facilities or the tightness of monetary policy at different times.

\section{Centrality}

Centrality measures the importance of a node in a network. In the case of interbank markets, centrality assists to understand not only the importance of a bank in terms of the volumes of liquidity coming from or going into it, but also on how important is a bank to the whole banking system. Centrality measures are used to compare banks with respect to their respective systemic importance as participants in the market. That is important in analyzing the smoothness of liquidity distribution in a given banking system as well as the levels of contagion in the market in times of a liquidity shock.

The study compares centrality of the banks in the network using degree centrality and betweenness centrality ${ }^{9}$. Degree centrality shows how many links come from and go into a node. That shows the connectivity of a node and the distribution of the degree centrality can give implication on properties of the network structure. Since interbank networks are directed, the distributions of in-degree and out-degree are analyzed in the study. The individual bank clustering coefficients take into account the borrowing and lending activity of each of the banks and its counterparts. They therefore determine the relative importance of a bank within the network. Using this measure, banks that are important to the flow of funds are the ones that are counterparts to other banks. Such banks obtain a higher centrality score. Thus, a systemically important bank will ${ }^{9}$ Other known centralities in the study of interbank markets include closeness and eigenvector centrality. 
be identified as a bank that is active in the interbank market by trading with other banks in the interbank market.

Betweenness centrality is a measure of node's importance to the network than just connectivity. It measures the number of shortest paths from all nodes to others passing through a node, particularly indicating the importance of the node in information transmission. Unlike individual banks clustering coefficient, betweenness centrality considers both direct and indirect relationships. Betweenness measures are based on the link structure of the network and measures the importance of a bank as intermediary in the network. The betweenness centrality of a node is therefore the probability that the node is used as an intermediary on the shortest path between any two other nodes. That measures the importance of a node in terms of the flows between other nodes in the network in both lending and borrowing. The more paths a node handles, therefore, the more central is this node in the network. Centrality betweenness is calculated as the fraction of shortest paths between all nodes that go through this node. Hence the higher the betweenness centrality measure, the more important the bank is as an intermediary in the network.

Table 3 shows that there is significant variation in importance of individual banks in terms of liquidity distribution. In 2018Q4, two banks could borrow from up to 8 banks in the Malawi interbank network while one bank could lend to all the remaining 9 institutions in the market. This shows that while some banks have a wide choice of where to borrow from and lend to, some banks have narrower choice. This implies that the real impact of a liquidity shock to the whole market depend on which banks are affected. Similarly, bank 4 has the highest betweenness centrality of about 7.3 compared to bank 1 with the lowest betweenness centrality of just 0.2 . This shows that, while some banks are more important as intermediaries in the Malawi interbank market, some banks are less important.

Table 3. Nodes attributes as at 2018Q4.

\begin{tabular}{|c|c|c|c|c|c|c|c|c|c|c|c|c|}
\hline Id & indegree & outgree & Degree & Eccentricity & $\begin{array}{l}\text { Closness } \\
\text { centrality }\end{array}$ & $\begin{array}{c}\text { harmonicclosness } \\
\text { centrality }\end{array}$ & $\begin{array}{c}\text { betweeness } \\
\text { centrality }\end{array}$ & clustering & $\begin{array}{c}\text { eigen } \\
\text { centrality }\end{array}$ & $\begin{array}{l}\text { Weighted } \\
\text { indegree }\end{array}$ & $\begin{array}{l}\text { Weighted } \\
\text { outdegree }\end{array}$ & $\begin{array}{c}\text { Weighted } \\
\text { Degree }\end{array}$ \\
\hline 0 & 6 & 7 & 13 & 2 & 0.82 & 0.89 & 2.37 & 0.70 & 0.80 & 0.99 & 1.19 & 2.18 \\
\hline 1 & 5 & 3 & 8 & 2 & 0.6 & 0.67 & 0.20 & 0.85 & 0.67 & 1.00 & 0.11 & 1.11 \\
\hline 2 & 6 & 6 & 12 & 2 & 0.75 & 0.83 & 1.68 & 0.73 & 0.75 & 0.99 & 0.68 & 1.67 \\
\hline 3 & 8 & 6 & 14 & 2 & 0.75 & 0.83 & 4.57 & 0.68 & 1 & 1.01 & 0.49 & 1.5 \\
\hline 4 & 8 & 8 & 16 & 2 & 0.9 & 0.94 & 7.30 & 0.63 & 0.98 & 0.99 & 2.16 & 3.15 \\
\hline 5 & 6 & 9 & 15 & 2 & 0.9 & 0.94 & 4.00 & 0.67 & 0.77 & 0.66 & 1.63 & 2.29 \\
\hline 6 & 7 & 6 & 13 & 2 & 0.75 & 0.83 & 2.20 & 0.71 & 0.86 & 1.00 & 1.15 & 2.15 \\
\hline 7 & 6 & 5 & 11 & 2 & 0.69 & 0.78 & 1.70 & 0.79 & 0.79 & 1.01 & 0.11 & 1.12 \\
\hline 8 & 5 & 4 & 9 & 2 & 0.64 & 0.72 & 0.60 & 0.70 & 0.64 & 1.00 & 0.61 & 1.615 \\
\hline 9 & 5 & 8 & 13 & 2 & 0.90 & 0.94 & 4.38 & 0.63 & 0.67 & 1.00 & 1.52 & 2.52 \\
\hline
\end{tabular}




\section{Average Path Length}

Interbank networks are associated with the small-world property where most nodes can be reached from the others via a small number of links. That indicates that the degree of intermediation between net demanders of funds and net suppliers is small (Bech \& Atalay, 2010). In the study of interbank networks, path helps to measure how close nodes are to one another at any given time. A path is a sequence of nodes and links beginning and ending with nodes, where any link or node is not included more than once.

The length of a path is measured by its number of links and reflects the course that liquidity or contagion could follow. The distance between a pair of nodes is the length of the shortest path connecting them. Average shortest path is defined as the average number of links to reach any other bank in the network on the shortest path. Longest-path-length in/out provide further descriptions of the distance between nodes. The Longest-path-length of a node is length of the longest path originating in the node. The Longest-path-length can provide an indication of how easily or quickly an event affecting one node could potentially affect the other nodes in the network. For example, if one participant fails to send payments, participants with direct relationships with it might find themselves short of liquidity sooner than those who have only indirect relationships with that participant.

From Figure 9, the shortest average paths length of 1.244 is observed in 2018Q3 while the longest average path length of 1.842 is observed 2010Q4. As at 2018Q4 the average path length stood at 1.322, implying that on average, banks in the interbank market expect funds to switch hands up to 0.322 (1.322-1) more times.

\section{Conclusions and Implications}

From the interbank network characteristics analyzed in the study, we observe that Malawi's interbank market network has not been stable between 2010Q1 and 2018Q4 although the number of participating banks has been stable in most cases. Generally, the network for Malawi's interbank market is fairly dense with a significantly high clustering and a small average path length. The implication of this network structure is that liquidity is able to flow efficiently around the banking system. The network characteristics further unveil that entry or exit of a bank, for most of the times, has little impact on the ability of other banks to lend and borrow from one another. The high connectivity of the network will have contributed to this resilience. However, we note that changes to central bank's monetary policy stance have a significant impact on the connectivity of the interbank network.

The network structure also shows that failure of the one bank to supply liquidity to the system may not result into serious disruption in payments elsewhere in the network. This, however, also depends on the amount of liquidity available in the market as whole at the specific period in time. In situations 


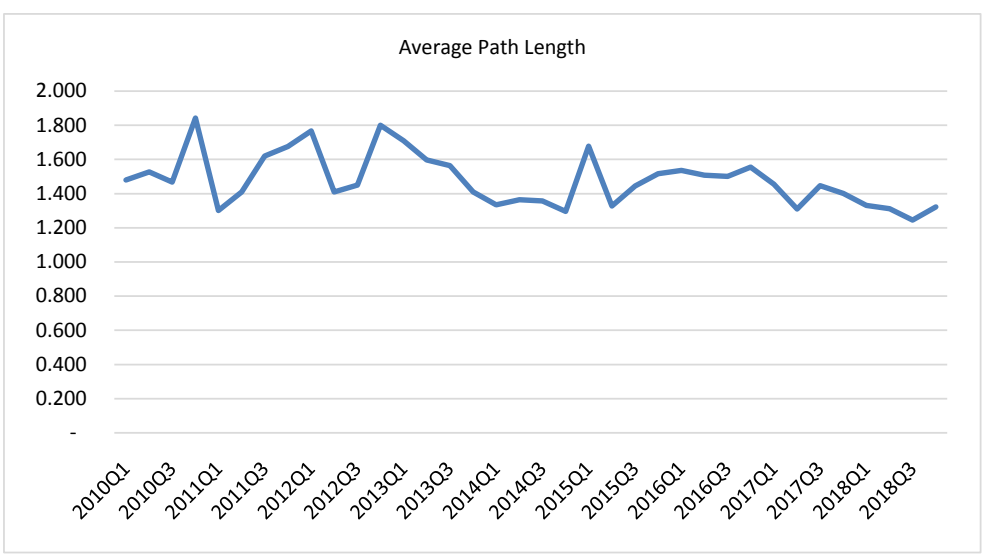

Figure 9. Movement in average path length (2010Q1-2018Q4).

where liquidity levels are limited, banks are able to make use of alternative sources of liquidity. Such sources include discounting of securities and accessing the central bank's Lombard facility. However, because the banks are different in importance, there is possibility that the operational disruption of some banks, especially if they are net suppliers of liquidity to the system, would have a more severe impact on the payment network than disruption of some less important banks.

The fact that the market is not a fully connected network may be an indication that some banks withhold lending to other banks. This is also in support of the situation where some banks access the central bank's standing facility even when some banks have the liquidity. This is indicative of the ability of interbank participating banks to monitor each other's behaviour which may also be aided by the small membership of registered banks in the country. That may also be due to the fact that individual banks have bilateral limits to how much they can lend or borrow from each other in the interbank market. On the other hand, the relatively high clustering and a small average path length make the interbank participating banks more vulnerable to contagion than random networks. Because of the strong connectivity, the network may not be resilient to an operational shock affecting one of the banks. In that case, the impact of an operational shock may be felt not just on the connectivity of the network but rather on the availability of liquidity with which to make payments. This may be hazardous to the whole banking system.

\section{Acknowledgements}

This research was supported by funds from the ESRC and the former UK Department for International Development, which merged with the Foreign \& Commonwealth Office on 2 September 2020 to become the Foreign, Commonwealth \& Development Office (FCDO). The views expressed in this study are those of the author and do not reflect the views of the Reserve Bank of Malawi, the ESRC or the FCDO. 


\section{Conflicts of Interest}

The author declares no conflicts of interest regarding the publication of this paper.

\section{References}

Anand, K., Craig, B., \& Von Peter, G. (2015). Filling in the Blanks: Network Structure and Interbank Contagion. Quantitative Finance, 15, 625-636. https://doi.org/10.1080/14697688.2014.968195

Bech, M. L., \& Atalay, E. (2010). The Topology of the Federal Funds Market. Physica A: Statistical Mechanics and its Applications, 389, 5223-5246. https://doi.org/10.1016/j.physa.2010.05.058

Becher, C., Millard, S., \& Soramaki, K. (2008). The Network Topology of CHAPS Sterling (p. 355). London: Bank of England. https://doi.org/10.2139/ssrn.1319277

Blasques, F., Bräuning, F., \& van Lelyveld, I. (2018). A Dynamic Network Model of the Unsecured Interbank Lending Market. Journal of Economic Dynamics and Control, 90, 310-342. https://doi.org/10.1016/j.jedc.2018.03.015

Borgatti, S. P., \& Everett, M. G. (2000). Models of Core/Periphery Structures. Social Networks, 21, 375-395. https://doi.org/10.1016/S0378-8733(99)00019-2

Brassil, A., \& Nodari, G. (2018). A Density-Based Estimator of Core/Periphery Network Structures: Analyzing the Australian Interbank Market. Reserve Bank of Australia, Research Discussion Paper RDP 2018-01.

Brink, N., \& Georg, C. (2011). Systemic Risk in South African Interbank Market. South Africa Reserve Bank Discussion Paper, DP/11/01.

Brunetti, C., Harris, J. H., Mankad, S., \& Michailidis, G. (2015). Interconnectedness in the Interbank Market. Finance and Economics Discussion Series, Washington DC: Divisions of Research \& Statistics and Monetary Affairs, Federal Reserve Board. https://doi.org/10.17016/FEDS.2015.090

Colliard, J., Foucault, T., \& Hoffmann, P. (2016). Trading Frictions in the Interbank and the Central Bank. http://www.eief.it/files/2016/06/colliard.pdf

Craig, C., \& von Peter, G. (2014). Interbank Tiering and Money Center Banks. Journal of Financial Intermediation, 23, 322-347. https://doi.org/10.1016/j.jfi.2014.02.003

Dospinescu, O. (2012). Mobile Payments. From Mobility to Security. The Young Economists Journal, 19, 190-193.

Gabrieli, S., \& Georg, C. (2016). A Network View on Interbank Market. Deutsche Bundesbank Discussion Paper, 44/2014. https://doi.org/10.2139/ssrn.2544603

Oduor, J., Sichei, M., Tiriongo, S., \& Shimba, C. (2014). Segmentation and Efficiency of the Interbank Market and Their Implication for the Conduct of Monetary Policy. Abidjan: African Development Bank, Working Paper Series 202.

Poole, W. (1968). Commercial Bank Reserves Management in Stochastic Model: Implications for Monetary Policy. Journal of Finance, 23, 769-791. https://doi.org/10.1111/j.1540-6261.1968.tb00316.x

Roukny, T., Georg, C. P., \& Battiston, S. (2014). A Network Analysis of the Evolution of the German Interbank Market. Deutsche Bundesbank Discussion Paper, 22/2014.

Sahabat, I., Silalahi, T., Indrastutil, R., \& Herlina, M. (2017). Network Motif of Interbank Payment as Early Warning Signal of Liquidity Crisis: Directed Random Graph and Directed Configuration Model Approaches. Bank of Indonesia Working Paper, LHP/2017. 
Schumacher, S. (2016). Network and Lending Conditions: Empirical Evidence from Swiss Franc Money Market. Swiss National Bank Working Paper, 12/2016.

Soramaki, K., Bech, M. L., Arnold, J., Glass, R. J., \& Beyeler, W. E. (2006). The Topology of Interbank Payment Flows (p. 243). Staff Report, New York: Federal Reserve Bank of New York.

Tiriongo, S., \& Kanyumbu, E. (2019). Interbank Market Discipline and Its Effectiveness: Case Study of Kenya and Malawi. AERC Research Paper 367, Nairobi: African Economic Research Consortium.

Vandermarliere, B., Karas, A., Ryckebusch, J., \& Schoors, K. (2015). Beyond the Power Law: Uncovering Stylized Facts in Interbank Networks. Physica A: Statistical Mechanics and Its Applications, 428, 443-457. https://doi.org/10.1016/j.physa.2015.01.058

$\mathrm{Xu}$, Z. (2016). Identifying Systemic Risk in Interbank Markets by Applying Network Theory. PhD Thesis, Bath: University of Bath. 